\title{
Macroeconomics with Endogenous Markups and Optimal Taxation
}

\author{
Federico Etro*
}

\begin{abstract}
I augment a flexible price dynamic general equilibrium model with any symmetric intratemporal preferences over a variety of goods supplied under monopolistic, Bertrand, or Cournot competition to derive implications for business cycle and market inefficiencies. Endogenous markups can magnify the impact of shocks on consumption and labor supply through intertemporal substitution mechanisms, and the optimal fiscal policy requires a variable labor income subsidy and a capital income tax that converges to zero in the long run. With an endogenous number of goods and strategic interactions, entry also affects markups and the optimal fiscal policy requires also a tax on profits. I characterize equilibrium and efficient market structures and derive optimal tax rules for a variety of preferences, including a new type of general additive preferences that nest direct, indirect, implicit, and homothetic additivity.
\end{abstract}

JEL Classification: E1, E2, E3

\section{Introduction}

I develop a flexible price macroeconomic model with imperfect competition that departs from the ubiquitous assumption of constant elasticity of substitution (CES) preferences $\grave{a}$ la Dixit and Stiglitz (1977) over a variety of goods and adopts general intratemporal preferences to examine business cycle implications and market inefficiencies. The purpose is not generalization per se, but the introduction of a new role for the demand side (through preferences) and the supply side (through strategic interactions and entry) in affecting macroeconomic behavior and the study of associated distortion and corrective taxation.

The model generates markups variable over time in the production level of each good and, when endogenized, in the number of goods produced. This is in sharp contrast with standard flexible price models, and allows me to obtain endogenously either countercyclical markups, which appear in line with wide aggregate evidence, for instance in Bils (1987) and more recently in Rotemberg and Woodford (2000) and Chevalier et al. (2003) and amplify the propagation of supply shocks, ${ }^{1}$ or procyclical markups, recently emphasized by Nekarda and Ramey (2013), Stroebel and Vavra (2018), and Anderson et al. (2018) in connection with demand shocks. Markup movements deliver new intertemporal inefficiencies in labor supply and in the savings choice, which affect the process of capital accumulation and, when endogenous, the process of business creation. Optimal

\footnotetext{
* University of Florence and Charles River Associates, 8 Finsury Circus, EC2M7/EA, London, UK; E-mail: fetro@crai.com.

Received December 2017; accepted May 2018.

${ }^{1}$ Of course, other explanations for countercyclical markups are possible. These are usually obtained introducing imperfect collusion between firms (Rotemberg and Woodford 1992, 2000), dynamic externalities in consumption (Ravn et al. 2006), changes in the number of goods (Bilbiie et al. 2012), or nominal rigidities (in the New-Keynesian literature). An empirical evaluation of the different channels is, however, beyond the scope of this theoretical work.
} 
taxation in this environment requires a variable labor income subsidy, a capital income tax which vanishes only in the long run and when entry is endogenous, and a tax on dividends. I characterize equilibrium and optimal taxes for a variety of intratemporal preferences: in particular, these include the general classes of directly additive, indirectly additive and homothetic aggregators, and I also propose a new type of general additivity that nests these classes.

The dynamic stochastic general equilibrium (DSGE) model is standard on the supply side, with constant returns to scale in the production of intermediate goods. These are sold under perfect competition to final goods producers that can be engaged in monopolistic, Bertrand, or Cournot competition, each one producing a single variety. The main novelties are on the demand side, where intratemporal preferences over the final goods can be any symmetric preferences, as in the static microfoundation of product differentiation developed in Bertoletti and Etro $(2015,2016)$. This allows the framework to nest a variety of flexible price models, including the standard neoclassical real business cycle (RBC) model with perfect competition in homogenous goods started by Kydland and Prescott (1982), models based on CES preferences and monopolistic competition started by Blanchard and Kiyotaki (1987) and developed in the New-Keynesian literature, and models with endogenous entry based on homothetic preferences (Bilbiie et al. 2012). The microfoundation, however, covers also any nonhomothetic preferences over differentiated products which generate a new role for the demand side in the propagation of the business cycle.

To exemplify the positive and normative implications of endogenous markups, I start from models with a fixed number of goods, as standard in general equilibrium analysis. In this case, the markups depend on the elasticity of the demand function implicit in the intratemporal preferences, which is constant with CES preferences and a function of the aggregate consumption level when preferences are nonhomothetic. When this elasticity is increasing in consumption, markups are countercyclical and the real wage is procyclical. This implies that the propagation of any temporary shock is magnified through new intertemporal substitution mechanisms: in practice consumers anticipate consumption and work more to gain from temporarily lower prices and temporarily higher wages. The opposite happens when the elasticity is decreasing in consumption. Instead, traditional constant markups generate the same propagation mechanisms as under perfect competition: this is why traditional flexible price models of monopolistic competition based on CES (as well as any homothetic) preferences behave just as under perfect competition except for a reduced labor supply.

The variability of markups over time is inefficient in an aggregate perspective, therefore both labor and capital income taxes are needed to restore optimality whenever preferences are not homothetic. For instance, preferences represented by a quadratic direct utility (à la Melitz and Ottaviano 2008) require variable subsidies on both labor and capital income along the growth path. Directly additive aggregators (i.e., with a separable direct utility à la Dixit-Stiglitz) require a countercyclical labor subsidy and a positive capital income tax if and only if markups are countercyclical, that is, the elasticity of marginal utility is decreasing in consumption. Instead, indirectly additive aggregators (i.e., with a separable indirect utility as in Bertoletti and Etro 2017) obtain the same results if the demand elasticity is decreasing in the prices. I present a variety of examples for different classes of preferences that are largely unexplored in macroeconomics and characterize the optimal taxation in each case. I also propose a new type of general additive preferences that nests direct additivity, indirect additivity, generalized additivity (Pollak 1972; Gorman 1987), homothetic additivity (Kimball 1995), and implicit additivity (Hanoch 1974), including the unexplored class of implicit CES preferences, which can be useful for future quantitative exercises. While the scope of 
this work is only methodological, Cavallari and Etro (2017) provide a first quantitative assessment of models based on directly additive preferences in both closed and open economies subject to productivity shocks and show that endogenous countercyclical markups can contribute in a substantial way to improve the performance of RBC models.

When entry of firms producing new goods is endogenous (as in Etro and Colciago 2010, or Bilbiie et al. 2012), markups depend on the consumption of each good, namely on the production of each firm, as well as on the number of goods. Investment is split between capital accumulation and business creation to equate their expected returns, and the steady state is typically reached through an increase in the stock of capital and the number of firms, with the production of each good declining over time. This is what maintains the equality of the returns, with the return on capital investment decreasing because the marginal productivity of capital goes down, and the return on business creation decreasing because the profits on each new variety diminish, while the number of varieties expands. Also in this case the markups are typically variable over the business cycle and the entry process, which generates an additional channel of propagation of the shocks and can be biased by either excessive or insufficient entry. I characterize the social planner solution for this framework and derive the optimal taxation that restores it in the decentralized equilibrium. This requires labor and capital income taxes as well as a tax on dividends (or profits): all of these taxes depend on the production of each good and the number of the firms. Besides deriving general tax rules, I characterize them for particular classes of preferences. For instance, under directly (indirectly) additive preferences the optimal profit tax is positive if and only if the elasticity of the subutility is decreasing in consumption (increasing in the price). With homothetic preferences, I already know from Bilbiie et al. (2016) that the optimal taxes depend only on the number of firms, but under specific classes of homothetic aggregators, I can derive explicit expressions for the optimal taxes and conditions for the profit tax to be positive or negative. I complete the analysis with the cases of Bertrand and Cournot competition, which add procompetitive effects of entry and require amendments to the optimal taxation rules. I can summarize the general principles emerging from the analysis in what appears to be the empirically plausible case:

As long as markups are countercyclical due to demand side mechanisms (changes in demand elasticity) or supply side mechanisms (changes in the strength of competition), labor income taxation should be countercyclical, capital income taxation should be positive and decreasing toward zero in the long run, and dividend taxation should be positive if markups are too high.

My analysis builds on recent theoretical advances. On the microeconomic front, the wide literature on dynamic consumption theory in partial equilibrium has already analyzed a variety of preference specifications (for an interesting treatment with direct additivity see, for instance, Browning and Crossley 2000), but has usually neglected implications for pricing under imperfect competition and its feedback on consumption. I mainly build on the industrial organization literature which has provided more general microfoundations to imperfect competition. In particular, while Dixit and Stiglitz (1977) formalized monopolistic competition when the direct utility is additive generalized separability (Gorman 1987) can be analyzed similarly; ${ }^{2}$ Benassy (1997) has considered monopolistic competition with homothetic preferences, and Bertoletti and Etro (2017) with an indirect utility, which is additive. ${ }^{3}$ Bertoletti and Etro $(2015,2016)$ have put together these and more general preferences in a unique framework studying equilibrium and optimal market structures, and here I use

\footnotetext{
${ }^{2}$ See Bertoletti and Etro (2018) for the case of Gorman-Pollak and implicit CES preferences under symmetry.

${ }^{3}$ See also Nocke and Schutz (2018) for an extension to strategic interaction.
} 
their framework to study dynamic market structures (see also Arkolakis and Morlacco 2017, Fally 2018, Bertoletti and Etro 2018, Dhingra and Morrow 2019 and Arkolakis et al., 2015 for other recent works generalizing the theory of monopolistic competition in static models).

Concerning the literature on macroeconomics with imperfect competition and optimal corrective taxation, most of the dynamic models with monopolistic competition have adopted the CES formulation, which delivers constant markups and implies that optimality can be reached with a constant subsidy to labor income. Notable exceptions include Kimball (1995), who has used a class of implicitly additive homothetic aggregators and Bilbiie et al. (2008), who have used translog preferences, but both these works have focused on sticky prices and monetary policy. Ravn et al. (2008) have used Stone-Geary directly additive preferences obtaining countercyclical markups. As far as I know, I provide the first theoretical analysis of the RBC model with general nonhomothetic intratemporal preferences and monopolistic competition. Moving to models with endogenous entry, the closest works in this spirit are by Bilbiie et al. $(2012,2016)$, who have analyzed a dynamic entry model with flexible prices, monopolistic competition, and homothetic aggregators to study business cycle and optimal taxation. ${ }^{4}$ Besides differences in modeling intermediate and final goods and entry costs, my main contribution compared to Bilbiie et al. (2012) is to depart from homothetic aggregators and consider general intratemporal preferences. As I have noticed, this has radical implications for the difference between perfect and imperfect competition, for the propagation of the shocks, and also for the analysis of the optimal taxation. ${ }^{5}$ Few other works on optimal taxation with imperfect competition and endogenous entry are only limited to the case of CES preferences and ignore capital accumulation and, therefore, capital income taxation. For instance, Lewis and Winkler (2015) have analyzed optimal taxation in a related but static environment, Bilbiie et al. (2016) have analyzed optimal corrective taxation in a dynamic environment without capital and with homothetic preferences, and Colciago (2016) has analyzed the optimal Ramsey taxation in an economy without capital (in the tradition of Lucas and Stockey 1983) assuming CES preferences with monopolistic, Cournot and Bertrand competition. I will extend some of their results.

The rest of the work is organized as follows. Section 2 presents the model with general symmetric preferences and monopolistic competition over a finite number of goods considering in detail some relevant classes. Section 3 discusses the most general environment with endogenous entry and different forms of imperfect competition under general preferences. Section 4 is the conclusion.

\section{A Dynamic Model with General Preferences}

Let us consider an infinitely living agent with the following preferences:

$$
\mathbb{U}=\mathbb{E} \sum_{t=1}^{\infty} \beta^{t-1}\left[U\left(\mathbf{C}_{t}, n\right)-\frac{v L_{t}^{1+\frac{1}{\varphi}}}{1+\frac{1}{\varphi}}\right],
$$

\footnotetext{
${ }^{4}$ The first work in this literature is probably Chatterjee and Cooper (2014). See Ghironi (2018) for a review. In the literature on dynamic entry see also La Croce and Rossi (2014), Poutineau and Vermandel (2015), Savagar (2017), and Savagar and Dixon (2017) for interesting related investigations with imperfections in the goods market and in the financial market.

${ }^{5}$ Etro (2016a) has derived the generalized Euler equation for a Ramsey model with monopolistic competition, but without analyzing the business cycle implications in the presence of endogenous labor supply or endogenous entry of firms.
} 
where $\beta \in(0,1)$ is the discount factor, $\mathbb{E}[\cdot]$ is the expectations operator, $\mathbf{C}_{t} \equiv\left[C_{1 t}, C_{2 t}, \ldots, C_{n t}\right]$ is the $n$-dimensional consumption vector (where $n$ is large), and the disutility from labor supply $L_{t}$ is isoelastic with Frish elasticity $\varphi \geq 0$ and scale parameter $v \geq 0 .{ }^{6}$ A traditional specification of intratemporal preferences involves the log-CES utility:

$$
U(\mathbf{C}, n)=\log \left[\sum_{j=1}^{n} C_{j}^{\frac{\theta-1}{\theta}}\right]^{\frac{\theta}{\theta-1}},
$$

where $\theta>1$ is interpreted as the intratemporal elasticity of substitution between goods and the intertemporal elasticity of substitution is unitary due to the logarithmic transformation. I will depart from this specification assuming that the period utility from consumption $U\left(\mathbf{C}_{t}, n\right)$ can be any symmetric, increasing and quasi-concave function of the consumption vector.

The production side is standard. Capital $K_{t}$ and labor supply $L_{t}$ are entirely employed by a perfectly competitive sector producing an intermediate good with a constant return to scale production function:

$$
Y_{t}=A_{t} F\left(K_{t}, L_{t}\right),
$$

where $A_{t}$ is total factor productivity. The intermediate good is the numeraire of the economy and can be used to invest in a standard process of capital accumulation with depreciation rate $\delta \in(0,1)$, or to produce final goods with a linear technology.

Each variety $i$ is sold at price $p_{i t}$ generating profits $\pi_{i t}=\left(p_{i t}-1\right) C_{i t}$. The consumer receives all the profits as dividends, $\Pi_{t}=\sum_{j=1}^{n} \pi_{j t}$, and the remuneration of the inputs. The markets for the factors of production are perfectly competitive. The labor market implies the wage $w_{t}=A_{t} F_{L}\left(K_{t}, L_{t}\right)$, and the capital market implies the rental rate $r_{t}=A_{t} F_{K}\left(K_{t}, L_{t}\right)$, always in units of intermediate good. In each period, the consumer chooses spending on each variety $C_{j t}$ for $j=1,2, \ldots, n$, labor supply $L_{t}$, and the future stock of capital $K_{t+1}$ to maximize utility under the resource constraint:

$$
K_{t+1}=K_{t}(1-\delta)+w_{t} L_{t}+r_{t} K_{t}+\Pi_{t}-\sum_{j=1}^{n} p_{j t} C_{j t},
$$

where total profits $\Pi_{t}$ and prices of final goods and inputs are taken as given.

The FOCs for $C_{j t}, L_{t}$, and $K_{t+1}$ are:

$$
U_{i}\left(\mathbf{C}_{t}, n\right)=\lambda_{t} p_{i t} \text { for } \mathrm{i}=1, \ldots, \mathrm{n},
$$

where $U_{i}\left(\mathbf{C}_{t}, n\right)=\partial U\left(\mathbf{C}_{t}, n\right) / \partial C_{i t}$ is the marginal utility of consumption of good $i$ and the Lagrange multiplier $\lambda_{t}$ corresponds to the marginal utility of income,

$$
v L_{t}^{\frac{1}{\varphi}}=\lambda_{t} w_{t}
$$

\footnotetext{
${ }^{6}$ Homothetic preferences that are identical across agents are essential for aggregation of the demand functions into a single demand function (of a so-called "representative agent"). As heterogeneity in preferences and the computational problem of aggregating demand functions are not my concern here, I assume that there is a single agent in the economy.
} 
and

$$
\lambda_{t}=\beta \mathbb{E}\left[R_{t+1} \lambda_{t+1}\right]
$$

where $R_{t+1}=1+r_{t+1}-\delta$ is the gross return on capital.

For a given expenditure $E_{t}=\sum_{j=1}^{n} p_{j t} C_{j t}$ at time $t$, the first order conditions 5 can be written in terms of the Hotelling-Wold identity:

$$
p_{i t}=\frac{U_{i}\left(\mathbf{C}_{t}, n\right) E_{t}}{\sum_{j=1}^{n} C_{j t} U_{j}\left(\mathbf{C}_{t}, n\right)} \mathrm{i}=1, \ldots, \mathrm{n}
$$

which is the inverse demand system. This can be inverted to obtain the system of Marshallian demand functions depending on the price vector $\mathbf{p}_{t} \equiv\left[p_{1 t}, p_{2 t}, \ldots, p_{n t}\right]$ and expenditure $E_{t}$. The corresponding demand vector is $\mathbf{C}_{t}\left(\mathbf{s}_{t}\right)$, where $\mathbf{s}_{t}=\mathbf{p}_{t} / E_{t}$ is the vector of price-expenditure ratios. This allows us to define the intratemporal preferences also in terms of the indirect utility function $V\left(\mathbf{s}_{t}\right.$, $n) \equiv U\left(\mathbf{C}_{t}\left(\mathbf{s}_{t}\right), n\right)$, where expenditure is the fruit of intertemporal allocation across periods. In this dual perspective, the demand for each good can be derived through the Roy's identity:

$$
C_{i t}=\frac{V_{i}\left(\mathbf{s}_{t}, n\right)}{\sum_{j=1}^{n} s_{j t} V_{j}\left(\mathbf{s}_{t}, n\right)} \mathrm{i}=1, \ldots, \mathrm{n},
$$

where $V_{i}\left(\mathbf{s}_{t}, n\right) \equiv \partial V\left(\mathbf{s}_{t}, n\right) / \partial s_{i t}$. Accordingly, preferences in Equation 1 can be expressed equivalently with the mixed utility:

$$
\mathbb{U}=\mathbb{E} \sum_{t=1}^{\infty} \beta^{t-1}\left[V\left(\mathbf{s}_{t}, n\right)-\frac{v L_{t}^{1+\frac{1}{\varphi}}}{1+\frac{1}{\varphi}}\right],
$$

in which case total expenditure $E_{t}$ and labor supply $L_{t}$ become the choice variables for the consumer in each period $t$, with consumption allocated to goods according to the Roy's identity above.

\section{Perfect Competition as a Benchmark}

Perfect competition in the production of each differentiated good implies $p_{i t}=1$ for each $i$ in each period $t$, so that consumption is also symmetric, $C_{i t}=C_{t}$ for any $i$, and Equation 5 delivers a marginal utility of income given by:

$$
\lambda=U_{i}(\mathbf{C}, n)=\frac{\partial U(C \mathbf{l}, n)}{\partial C_{i}} \equiv U_{i}(C, n)
$$

(with $\mathbf{t}$ as the $n$-dimensional unit vector), which is just the marginal utility of consumption for each good under symmetry. Accordingly, the equilibrium equations under perfect competition can be expressed as:

$$
U_{i}\left(C_{t}, n\right)=\beta \mathbb{E}\left\{\left[1+A_{t+1} F_{K}\left(K_{t+1}, L_{t+1}\right)-\delta\right] U_{i}\left(C_{t+1}, n\right)\right\}
$$




$$
\begin{aligned}
L_{t} & =\left[\frac{A_{t} F_{L}\left(K_{t}, L_{t}\right) U_{i}\left(C_{t}, n\right)}{v}\right]^{\varphi} \\
K_{t+1} & =K_{t}(1-\delta)+A_{t} F\left(K_{t}, L_{t}\right)-n C_{t},
\end{aligned}
$$

which is a straightforward generalization of the traditional RBC framework to multiple goods, where symmetry (and love for variety) implies that total consumption is equally divided between all goods. The concavity of the $U_{i}(C, n)$ function in consumption and the transversality condition are necessary and sufficient to guarantee the existence of a unique deterministic steady state with a saddle-path stable equilibrium.

\section{Monopolistic Competition}

Under monopolistic competition, each firm producing a variety $i$ maximizes its profits $\pi_{i t}=\left(p_{i t}-1\right) C_{i t}$ either with respect to the consumption level $C_{i t}$ or the price $p_{i t}$ considering only its direct effects on the demand. Using Equation 5, this allows one to express profits as:

$$
\pi_{i t}=\left(p_{i t}-1\right) C_{i t}=\left[\frac{U_{i}\left(\mathbf{C}_{t}, n\right)}{\lambda_{t}}-1\right] C_{i t}
$$

which is maximized by choosing the optimal consumption taking as given the marginal utility of income $\lambda_{t}$. The problem was first addressed by Dixit and Stiglitz (1977) when the utility is additively separable (namely $U_{i j}\left(\mathbf{C}_{t}, n\right)=0$ for $j \neq i$ ), but can be solved also in the general nonseparable case (see Bertoletti and Etro 2016, Prop. 1). The symmetric equilibrium price can be derived as:

$$
p_{t}=\frac{1}{1-\epsilon\left(C_{t}, n\right)}
$$

where the relevant elasticity is the Morishima elasticity of complementarity between goods (as defined in Blackorby and Russell 1981):

$$
\epsilon(C, n)=-\frac{\partial \ln \left(p_{i} / p_{j}\right)}{\partial \ln C_{i}}
$$

with $p_{i}=p_{j}$. Direct computation from $p_{i} / p_{j}=U_{i}(\mathbf{C}, n) / U_{j}(\mathbf{C}, n)$ allows one to obtain an expression for this elasticity, which is assumed less than unitary to guarantee a well defined price:

$$
\epsilon(C, n)=\frac{-C U_{i i}(C, n)}{U_{i}(C, n)}+\frac{C U_{i j}(C, n)}{U_{j}(C, n)}<1,
$$

where $U_{i j}(C, n) \equiv \frac{\partial^{2} U(C \mathbf{u}, n)}{\partial C_{i} \partial C_{j}}$. In case of CES preferences as in Equation 2, this elasticity is a constant, $\epsilon(C, n)=1 / \theta$, which explains why monopolistic prices are given by constant markups $p_{t}=\frac{\theta}{\theta-1}$. In general, however, the Morishima elasticity can be either increasing or decreasing in consumption, therefore markups can be either procyclical or countercyclical. Countercyclicality is the case that appears more in line with the evidence from Bils (1987) to Rotemberg and Woodford (2000) and Chevalier et al. (2003), but I do not commit to this in what follows.

I should remark that a misleading interpretation of the so-called Marshall's second law of demand suggests that demand should be more elastic (and markup should be higher) at higher 
levels of aggregate consumption. However, the second law was only a conjecture occasionally mentioned by Marshall (and not supported by systematic evidence); it was conjectured for a given demand curve and not when the aggregate consumption of all goods changes (as here), and there is no convincing intuition for which the demand elasticity should not be constant (as it is with CES preferences) or increasing in consumption (as when the elasticity of complementarity $\epsilon(C, n)$ decreases in $C$ ). In an intertemporal framework it is indeed quite reasonable to perceive goods as poor substitutes when they are consumed in small quantities, and as more easily substitutable when each one is consumed in a larger quantity: in other words, richer consumers are less risk averse and less lovers of differentiation. Under these circumstances markups are countercyclical because firms perceive demand as more elastic when aggregate consumption increases. Under the opposite circumstances markups are variable and procyclical (see Bertoletti et al. 2017 for further discussion on the second law of demand of Marshall).

When intratemporal preferences are expressed in terms of the indirect utility $V\left(\mathbf{s}_{t}, n\right)$, Bertoletti and Etro (2016, Prop. 1) have shown that the relevant elasticity can be expressed as $\epsilon(C, n)=1 / \theta(s, n)$, where $s \equiv p / E$ and $\theta(s, n)=-\partial \ln \left(C_{i} / C_{j}\right) / \partial \ln s_{i}$ is the Morishima elasticity of substitution between goods with $C_{i}=C_{j}$, which again can be either increasing or decreasing. ${ }^{7}$ In this perspective the equilibrium price solves $p_{t}=1 /\left(1-1 / \theta\left(s_{t}, n\right)\right)$, where the symmetric budget constraint implies $s_{t}=p_{t} / E_{t}=1 / n C_{t}$.

As long as the number of goods is fixed, prices change only with aggregate consumption, which affects the dynamic evolution of the economy. Solving for the marginal utility of income obtains:

$$
\lambda_{t}=\frac{U_{i}\left(C_{t}, n\right)}{p_{t}}=U_{i}\left(C_{t}, n\right)\left[1-\epsilon\left(C_{t}, n\right)\right]
$$

I can replace this expression in the Euler and labor supply conditions and obtain the equilibrium system under monopolistic competition. This is summarized in:

Proposition 1. In a dynamic model with general intratemporal preferences and monopolistic competition over an exogenous number of goods the equilibrium satisfies:

$$
\begin{gathered}
U_{i}\left(C_{t}, n\right)\left[1-\epsilon\left(C_{t}, n\right)\right]=\beta \mathbb{E}\left\{R_{t+1} U_{i}\left(C_{t+1}, n\right)\left[1-\epsilon\left(C_{t+1}, n\right)\right]\right\} \\
L_{t}=\left[\frac{A_{t} F_{L}\left(K_{t}, L_{t}\right) U_{i}\left(C_{t}, n\right)\left[1-\epsilon\left(C_{t}, n\right)\right]}{v}\right]^{\varphi} \\
K_{t+1}=K_{t}(1-\delta)+A_{t} F\left(K_{t}, L_{t}\right)-n C_{t}
\end{gathered}
$$

where $\epsilon(C, n)$ is the Morishima elasticity of complementarity.

The condition that $U_{i}(C, n)[1-\epsilon(C, n)]$ is decreasing in consumption insures saddle-path stability and will be verified in the examples below. Essentially, this requires that the function $U(C, n)$ is concave enough in the symmetric consumption level. The new component of the equilibrium system under monopolistic competition is the Morishima elasticity $\epsilon(C, n)$, which governs the markup

\footnotetext{
${ }^{7}$ Direct computation from $C_{i} / C_{j}=V_{i}(\mathbf{s}, n) / V_{j}(\mathbf{s}, n)$ shows that:

$\theta(s, n) \equiv \frac{s V_{i i}(s, n)}{V_{j}(s, n)}-\frac{s V_{i i}(s, n)}{V_{i}(s, n)}>1$

under symmetry, where I defined symmetric derivatives as before.
} 
rule. When this is constant, as with CES preferences, the Euler equation remains identical to perfect competition, and market power has no bite on the dynamics.

When the Morishima elasticity $\epsilon(C, n)$ is decreasing in the consumption level, markups become countercyclical and this affects both savings and labor supply. In particular, a temporary boom associated with higher consumption determines a temporary reduction in markups. This reduces temporarily the relative price of goods and increases temporarily the real wage, which promotes both consumption and labor, magnifying the propagation of the boom. The opposite happens when the Morishima elasticity $\epsilon(C, n)$ is increasing in the consumption level. In general, endogenous markup variability affects the intertemporal choices of consumers, inducing substitution mechanisms that are absent under perfect competition or fixed markups.

\section{Social Planner Problem}

The variability of markups creates inefficiencies in the allocation of capital and labor over time. To evaluate them, consider the relevant social planner problem:

$$
\max _{K_{t+1}, L_{t}} \mathbb{E} \sum_{t=1}^{\infty} \beta^{t-1}\left[U\left(\frac{A_{t} F\left(K_{t}, L_{t}\right)-K_{t+1}+K_{t}(1-\delta)}{n}, n\right)-\frac{v L_{t}^{1+\frac{1}{\varphi}}}{1+\frac{1}{\varphi}}\right],
$$

where I have solved the symmetric resource constraint $K_{t+1}=K_{t}(1-\delta)+A_{t} F\left(K_{t}, L_{t}\right)-n C_{t}$ for consumption of each good and replaced the latter in the symmetric utility $U\left(C_{t}, n\right)$. The FOCs for $K_{t+1}^{*}$ and $L_{t}^{*}$ are:

$$
\frac{\frac{\partial U\left(C_{t}^{*}, n\right)}{\partial C_{t}}}{n}=\beta \mathbb{E}\left\{\frac{1}{n}\left[1+A_{t+1} F_{K}\left(K_{t+1}^{*}, L_{t+1}^{*}\right)-\delta\right] \frac{\partial U\left(C_{t+1}^{*}, n\right)}{\partial C_{t+1}}\right\}
$$

and

$$
v\left(L_{t}^{*}\right)^{\frac{1}{\varphi}}=\frac{A_{t} F_{L}\left(K_{t}^{*}, L_{t}^{*}\right)}{n} \frac{\partial U\left(C_{t}^{*}, n\right)}{\partial C_{t}} .
$$

An intuitive property of symmetric functions is that $\frac{\partial U(C \mathbf{l}, n)}{\partial C}=\sum_{j=1}^{n} \frac{\partial U(C \mathbf{l}, n)}{\partial C_{j}}$, which implies $n U_{i}(C, n)=\frac{\partial U(C, n)}{\partial C}$ and allows me to rewrite the optimality conditions as:

$$
U_{i}\left(C_{t}^{*}, n\right)=\beta \mathbb{E}\left\{\left[1+A_{t+1} F_{K}\left(K_{t+1}^{*}, L_{t+1}^{*}\right)-\delta\right] U_{i}\left(C_{t+1}^{*}, n\right)\right\}
$$

and

$$
L_{t}^{*}=\left[\frac{A_{t} F_{L}\left(K_{t}^{*}, L_{t}^{*}\right) U_{i}\left(C_{t}^{*}, n\right)}{v}\right]^{\varphi}
$$

These conditions correspond, as expected, to the equilibrium conditions under perfect competition. This shows that monopolistic competition has introduced two sources of inefficiency. The first is a traditional intratemporal inefficiency due to underprovision of labor. The second is an 
intertemporal inefficiency due to the variability of markups over time (Lerner 1934). Ideally, markups for leisure and goods should be eliminated or set at a constant level over time, which is not what the monopolistic competition equilibrium delivers in general.

\section{Optimal Taxes with Monopolistic Competition}

In case of lump sum transfers/taxes available to balance the budget, I can find the tax rates on capital income and labor income that restore the first best allocation of resources. Let us introduce a subsidy on labor income $\tau_{t}^{L}$ and a tax rate on gross capital income $\tau_{t}^{K}$ at time $t$. The decentralized equilibrium conditions change as follows:

$$
\begin{gathered}
U_{i}\left(C_{t}, n\right)\left[1-\epsilon\left(C_{t}, n\right)\right]=\beta \mathbb{E}\left\{\left(1-\tau_{t+1}^{K}\right) R_{t+1} U_{i}\left(C_{t+1}, n\right)\left[1-\epsilon\left(C_{t+1}, n\right)\right]\right\} \\
L_{t}=\left[\frac{\left(1+\tau_{t}^{L}\right) A_{t} F_{L}\left(K_{t}, L_{t}\right) U_{i}\left(C_{t}, n\right)\left[1-\epsilon\left(C_{t}, n\right)\right]}{v}\right]^{\varphi}
\end{gathered}
$$

The optimal taxation can be derived by matching these equations and the first best ones, which immediately proves:

PROPOSITION 2. In a dynamic model with general intratemporal preferences and monopolistic competition over an exogenous number of goods the optimal labor and capital income taxes are:

$$
\tau_{t}^{L}=\frac{\epsilon\left(C_{t}, n\right)}{1-\epsilon\left(C_{t}, n\right)} \text { and } \tau_{t}^{K}=\frac{\epsilon\left(C_{t-1}, n\right)-\epsilon\left(C_{t}, n\right)}{1-\epsilon\left(C_{t}, n\right)}
$$

where $\epsilon(C, n)$ is the Morishima elasticity of complementarity.

The optimal tax rates can be directly computed as functions of the number of goods available and the production level of each firm once the Morishima elasticity is known. This confirms that in the traditional case of CES preferences a constant and negative labor income tax in each period is sufficient to establish optimality even in the presence of monopolistic distortions in the goods market. In general, however, variable labor and capital income taxes are needed. Only in steady state, the optimal taxation of capital income becomes zero for any preferences, supporting also under imperfect competition the traditional long-run optimality of zero capital income taxation (Chamley 1986).

Countercyclical tax rates on labor income emerge when the markups are countercyclical, because a boom reduces prices, increasing the real wages, which reduces the need to subsidize work. In this case, capital income should be taxed along the growth path to promote consumption and slow down excessive savings (due to high markups). While consumption grows, the markups decline and savings become less attractive relative to consumption, which reduces the optimal capital income taxation. In this sense also the capital income tax is countercyclical. The opposite happens if markups are procyclical.

Some examples of preferences will now clarify how one can characterize the dynamic behavior of the economy and the optimal taxes in this generalized environment.

\section{Quadratic Direct Utility}

Start with a simple specification of nonhomothetic and nonseparable preferences. The most familiar one is probably the case of a quadratic direct utility function: 


$$
U(\mathbf{C}, n)=\alpha \sum_{j=1}^{n} C_{j}-\gamma \sum_{j=1}^{n} \frac{C_{j}^{2}}{2}-\frac{\eta}{2}\left(\sum_{j=1}^{n} C_{j}\right)^{2}
$$

where $\eta \geq 0$ parametrizes the cross-substitutability; notice that only for $\eta=0$, I obtain an additive quadratic direct utility (see the discussion below). Similar preferences are often used in trade models with heterogeneous firms (see Melitz and Ottaviano 2008 for a quasilinear version) and have already been used by Ottaviano (2012) in a dynamic model, but without capital accumulation or endogenous labor supply.

In this case, $U_{i}(C, n)=\alpha-(\gamma+\eta n) C$ and the Morishima elasticity is $\epsilon(C, n)=\frac{\gamma C}{\alpha-(\gamma+n \eta) C}$, which is increasing in individual consumption as well as in the number of goods, due to nonadditivity. This delivers the monopolistic price:

$$
p_{t}=\frac{\alpha-(\gamma+n \eta) C_{t}}{\alpha-(2 \gamma+n \eta) C_{t}}
$$

which requires $C_{t}<\alpha /(2 \gamma+n \eta)$ for any $t$, and is increasing in consumption and in the number of goods. Under monopolistic competition, here is the modified Euler equation:

$$
\alpha-(2 \gamma+n \eta) C_{t}=\beta \mathbb{E}\left\{R_{t+1}\left[\alpha-(2 \gamma+\eta n) C_{t+1}\right]\right\} .
$$

In this case, the optimal taxation can be easily derived as:

$$
\tau_{t}^{L}=\frac{\gamma C_{t}}{\alpha-(2 \gamma+n \eta) C_{t}} \text { and } \tau_{t}^{K}=\frac{\alpha \gamma\left(C_{t-1}-C_{t}\right)}{\left[\alpha-(2 \gamma+n \eta) C_{t}\right]\left[\alpha-(\gamma+n \eta) C_{t-1}\right]}
$$

which provides a procyclical labor subsidy and negative capital income taxation on the growth path.

\section{Directly Additive Aggregators}

Consider the case where the intratemporal utility is a monotonic transformation $U(\cdot)$ of a directly additive aggregator:

$$
U(\mathbf{C}, n)=U\left(\sum_{j=1}^{n} u\left(C_{j}\right)\right) .
$$

Of course, when $U$ is a logarithmic function, there is the traditional specification (Eqn. 2) if $u$ is a power function. Interestingly, the general transformation $U(\cdot)$ affects intertemporal substitutability, but not intratemporal substitutability between goods. Indeed, in each period monopolistic pricing is:

$$
p_{t}=\frac{1}{1-\epsilon\left(C_{t}\right)}
$$

where the Morishima elasticity is just the elasticity of the marginal subutility $\epsilon(C)=\frac{-u^{\prime \prime}(C) C}{u^{\prime}(C)}$, which is also the relative risk aversion coefficient for this subutility function. The modified Euler condition can be expressed as:

$$
\frac{U^{\prime}\left(n u\left(C_{t}\right)\right) u^{\prime}\left(C_{t}\right)}{p_{t}}=\beta \mathbb{E}\left\{R_{t+1} \frac{U^{\prime}\left(n u\left(C_{t+1}\right)\right) u^{\prime}\left(C_{t+1}\right)}{p_{t+1}}\right\},
$$


where intertemporal substitutability depends on the variability of utility and prices. Optimal taxation requires:

$$
\tau_{t}^{L}=\frac{\epsilon\left(C_{t}\right)}{1-\epsilon\left(C_{t}\right)} \text { and } \tau_{t}^{K}=\frac{\epsilon\left(C_{t-1}\right)-\epsilon\left(C_{t}\right)}{1-\epsilon\left(C_{t}\right)}
$$

which is independent from the transformation function. The optimal labor income subsidy is countercyclical (procyclical) if the elasticity of marginal utility $\epsilon(C)$ is decreasing (increasing) in consumption. The optimal capital income tax rate is positive (negative) if the same elasticity is decreasing (increasing) and consumption is growing, but it always converges to zero in steady state.

Ravn et al. (2008) have adopted the Stone-Geary specification with subutility $u(C)=(C-\bar{C})^{\frac{\theta-1}{\theta}}$, where $\bar{C}>0$ is interpreted as a subsistence level. These preferences generate countercyclical markups because $\epsilon(C)=\frac{C}{\theta(C-\bar{C})}$ is decreasing in consumption, but the authors show that monopolistic competition delivers a moderate magnification of business cycle compared to perfect competition. Cavallari and Etro (2017) adopt a different formulation that nests CES preferences, with bi-power subutility $u(C)=\gamma C+\frac{\theta}{\theta-1} C^{\frac{\theta-1}{\theta}}$ and $\gamma>0,{ }^{8}$ which again generates countercyclical markups due to the elasticity $\epsilon(C)=\frac{1}{\theta\left(1+\gamma C^{1 / \theta}\right)^{2}}$. Estimating the preference parameters, the authors obtain a substantial magnification of business cycle propagation compared to perfect competition, suggesting that endogenous markups can contribute to improve the quantitative performance of RBC models. Notice that both these cases require countercyclical labor income subsidies and positive capital income taxation to restore optimality.

I present two additional examples. With the HARA subutility $u(C)=1-e^{-\chi C^{\frac{\theta-1}{\theta}}}$, which nests the CES case for and $\chi \rightarrow 0$ and $\theta \in(1, \infty)$, and the exponential case for $\theta \rightarrow \infty$ and $\chi>0$, I obtain an elasticity $\epsilon(C)=\frac{1}{\theta}\left[1+\chi(\theta-1) C^{\frac{\theta-1}{\theta}}\right]$ that is nondecreasing in consumption. ${ }^{9}$ Finally, with the subutility $u(C)=-(\alpha-C)^{1+\mathrm{e}}$ for $\mathrm{Q} \geq 0$, I obtain $\epsilon(C)=\frac{\mathrm{e} C}{\alpha-C}$, which is again increasing in consumption. ${ }^{10}$ In these two examples, monopolistic competition prices are procyclical and the propagation of any expansionary shock is actually dampened compared to perfect competition. Moreover, optimal taxation requires a procyclical labor subsidy and a negative capital income tax on the growth path.

\section{Indirectly Additive Aggregators}

A general class of preferences recently introduced in a static analysis of monopolistic competition is characterized by an indirect utility that is additive (Bertoletti and Etro 2017), as in:

$$
V\left(\frac{\mathbf{p}}{E}\right)=U\left(\sum_{j=1}^{n} v\left(\frac{p_{j}}{E}\right)\right),
$$

\footnotetext{
${ }^{8}$ This specification was originally introduced by Bertoletti et al. (2017) in the analysis of monopolistic competition.

${ }^{9}$ Monopolistic prices are $p_{t}=\frac{\theta}{(\theta-1)\left(1-\chi C^{\frac{\theta-1}{\theta}}\right)}$ when positive.

${ }^{10}$ Monopolistic prices are $p_{t}=\frac{\alpha-C_{t}}{\alpha-(1+\mathrm{e}) C_{t}}$ under the regularity condition $C_{t}<\alpha /(1+\mathrm{Q})$. Notice that the economy becomes approximately perfectly competitive for $\mathrm{Q} \rightarrow 0$, which implies almost perfect substitutability and marginal cost pricing by all firms, and the price increases with $\varrho$ which makes demand more inelastic.
} 
where $v(s)$ is the subutility of a normalized price $s=p / E$ with $v^{\prime}(s)<0$ and $v^{\prime \prime}(s)>0$, and $U(\cdot)$ is always a monotonic transformation that insures concavity in income.

In the Appendix, I show that the monopolistic price satisfies:

$$
p_{t}=\frac{\theta\left(1 / n C_{t}\right)}{\theta\left(1 / n C_{t}\right)-1}
$$

where $\theta(s) \equiv \frac{-v^{\prime \prime}(s) s}{v^{\prime}(s)}$ is the demand elasticity in function of the price-expenditure ratio that satisfies $s_{t}=1 / n C_{t}$ in symmetric equilibrium, so that $\epsilon(C, n)=\theta(1 / C n)$. The demand elasticity corresponds to what is defined above as the Morishima elasticity of substitution. The case of CES preferences emerges again if $\theta^{\prime}=0$, namely with $v(s)=s^{1-\theta}$ for $\theta>1$. In the Appendix, I derive the generalized Euler equation and analyze convenient specifications that deliver linear and loglinear demand functions with procyclical markups in line with the evidence of Stroebel and Vavra (2018) and Anderson et al. (2018). I also present a case of translated power preferences which delivers countercyclical markups.

The optimal taxation can be derived from the general principles stated above as follows:

$$
\tau_{t}^{L}=\frac{1}{\theta\left(s_{t}\right)-1} \text { and } \tau_{t}^{K}=\frac{\theta\left(s_{t}\right)-\theta\left(s_{t-1}\right)}{\theta\left(s_{t-1}\right)\left[\theta\left(s_{t}\right)-1\right]},
$$

where $s_{t}=p_{t} / E_{t}=1 / n C_{t}$. The labor subsidy is procyclical (countercyclical) and the capital income taxation is negative (positive) if $\theta^{\prime}>(<) 0$.

\section{Homothetic Aggregators}

Finally, assume that intratemporal preferences for consumption in Equation 1 can be expressed as:

$$
U(\mathbf{C}, n)=U[H(\mathbf{C}, n)],
$$

where without loss of generality, $H(\mathbf{C}, n)$ is a consumption index that is homogenous of degree one, and $U(\cdot)$ is an appropriate concave monotonic transformation. Again, I have as a particular case the specification Equation 2, when $U$ is a logarithmic function and $H(\mathbf{C}, n)$ is a CES aggregator.

Beyond the CES case, the class of preferences with homothetic aggregators includes other examples often used in macroeconomics, such as translog preferences (Feenstra 2003; Bilbiie et al. 2012) or Kimball (1995) aggregators. ${ }^{11}$ It is well-known (see for instance Benassy 1997) that the symmetric price of monopolistic competition for these preferences is a function of the number of goods $n$ only. As here the number of goods is exogenous, the price of the final goods:

$$
p_{t}=\frac{1}{1-\epsilon(n)}
$$

\footnotetext{
${ }^{11}$ Kimball (1995) considered implicitly additive production functions satisfying constant returns to scale, but the reinterpretation in terms of homothetic preferences is common in the literature.
} 
is indeed a constant. ${ }^{12}$ Therefore, the Euler equation remains identical to perfect competition. Using homogeneity, I have $H\left(C_{t} \mathbf{l}, n\right)=C_{t} H(\mathbf{l}, n)$ under symmetry, therefore the Euler equation can be written as:

$$
U^{\prime}\left(C_{t} H(\mathbf{l}, n)\right)=\beta \mathbb{E}\left\{R_{t+1} U^{\prime}\left(C_{t+1} H(\mathbf{l}, n)\right)\right\},
$$

while the labor supply is distorted downword by a constant in every period. This has an important implication. Under homothetic preferences, it is always optimal to adopt tax smoothing on labor income and zero taxation on capital income:

$$
\tau^{L}=\frac{\epsilon(n)}{1-\epsilon(n)} \text { and } \tau^{K}=0
$$

As seen in the next section, this will not be the case when the number of goods is endogenized.

\section{More General Additive Aggregators}

I conclude this section by proposing a new type of preferences that nests known versions of direct additivity, indirect additivity, homothetic additivity, generalized additivity (Pollak 1972; Gorman 1987), and implicit additivity (Hanoch 1974). Assume that the intratemporal preference aggregator is expressed by a direct utility $U$ defined implicitly as follows:

$$
U=\sum_{j=1}^{n} u\left(\xi C_{j}, U\right)-\frac{\xi^{1-\frac{1}{\rho}}-1}{1-\frac{1}{\rho}},
$$

where the subutility $u$ is increasing and concave in the adjusted consumption $\xi C_{j}$ of good $j$; that is, denoting derivatives with subscripts, $u_{j}>0>u_{j j}$ for any $j=1, . ., n$, and possibly depending on utility $U, \rho \in[0, \infty)$ and the aggregator $\xi$ satisfies:

$$
\xi^{-1}=\sum_{j=1}^{n} u_{j}\left(\xi C_{j}, U\right) C_{j}
$$

Further restrictions are needed to insure that preferences are well-behaved. Assuming this, utility maximization implies an inverse demand system:

$$
p_{i}=\frac{u_{i}\left(\xi C_{i}, U\right) E}{\sum_{j=1}^{n} u_{j}\left(\xi C_{j}, U\right) C_{j}}=u_{i}\left(\xi C_{i}, U\right) \xi^{\frac{1}{\rho}} E,
$$

which depends on two aggregators defined by Equations 34 and 35, namely on utility $U$ and on $\xi$. Assuming that firms maximize profits taking as given both aggregators, the relevant elasticity for monopolistic pricing under symmetry is:

\footnotetext{
${ }^{12}$ Markups are variable in Kimball (1995) because prices are not flexible and consumption varies across goods, and in Bilbiie et al. (2012) because the number of firms is variable.
} 


$$
\epsilon(C, n)=\frac{-u_{i i}(\xi C, U) \xi C}{u_{i}(\xi C, U)}
$$

which depends on the symmetric equilibrium values of the aggregators and on symmetric consumption $C$ and number of firms $n$ through them, and must be constrained to be smaller than one. Markup properties and optimal tax rules are based on this elasticity according to Propositions 1 and 2.

If $\rho \rightarrow 0, \xi=\lim _{\rho \rightarrow 0}\left[\sum_{j=1}^{n} u_{j}\left(\xi C_{j}, U\right) C_{j}\right]^{-\rho}=1$; therefore utility reduces to:

$$
U=\sum_{j=1}^{n} u\left(C_{j}, U\right) .
$$

This delivers implicit directly additive preferences (Hanoch 1974) for which $\epsilon(C, n)=\epsilon(C, U)$. If $u\left(C_{j}, U\right)=u\left(C_{j} / U\right) U$, there remains with a homothetic family of Kimball preferences associated with Kimball (1995), implying constant markups and optimal taxes. If $u_{U}=0$, there are directly additive preferences analyzed above. If instead $u\left(C_{j}, U\right)=\left(C_{j} / U\right)^{1-\frac{1}{\theta(U)}} U$ for some function $\theta(U)$ of the utility level, there is a version of the implicit CES preferences:

$$
U \equiv\left[\sum_{j=1}^{n} C_{j}^{\frac{\theta(U)-1}{\theta(U)}}\right]^{\frac{\theta(U)}{\theta(U)-1}}
$$

as defined in Hanoch (1974) and applied to monopolistic competition in Bertoletti and Etro (2018). Assuming $U(\mathbf{C}, n)=\log U$, this can be particularly useful for macroeconomic applications because it inherits the properties of log-CES formulation (Eqn. 2), while delivering variable markups. As $\epsilon(C, n)=1 / \theta(U)$ is the elasticity of substitution, markups and optimal tax rates are countercyclical if $\theta(U)$ is increasing in the intratemporal utility.

If $\rho \rightarrow 1$, which implies $\varphi(\xi)=\log \xi, 1=\sum_{j=1}^{n} u_{j}\left(\xi C_{j}, U\right) \xi C_{j}$. If $u_{U}=0$, the aggregator is homogeneous and I obtain a family of homothetic additive preferences, which include also a symmetric version of translog preferences (see Matsuyama and Ushchev 2017). This case delivers an equilibrium elasticity depending on the number of firms only.

If $\rho \rightarrow \infty$, which implies $\varphi(\xi)=\xi, 1=\sum_{j=1}^{n} u_{j}\left(\xi C_{j}, U\right) C_{j}$ and the inverse demand system simplifies to $p_{i}=u_{i}\left(\xi C_{i}, U\right) E$ or $C_{i}=u_{i}^{-1}\left(p_{i} / E, U\right) / \xi$. Substituting in the direct utility, the indirect utility $V$ can be expressed implicitly as:

$$
V=\sum_{j=1}^{n} v\left(s_{j}, V\right)
$$

for some subutility $v(s, V)$ of normalized price and utility. This implies implicit indirectly additive preferences (Hanoch 1974), including a homothetic family of Kimball preferences, indirectly additive preferences if $u_{U}=0$, and again the implicit CES preferences.

For a general function of the aggregator and $u_{U}=0$, there are Gorman-Pollak preferences, as applied to monopolistic competition in Bertoletti and Etro $(2015,2018),{ }^{13}$ and featuring an

\footnotetext{
13 See also Fally (2018) on the integrability of demand functions with a single aggregator.
} 
elasticity $\epsilon(C, n)=\epsilon(\xi C)$. In conclusion, this more general form of additivity nests GAS preferences as well as other preferences that feature a demand system with two (implicitly well-defined) aggregators.

\section{Dynamic Endogenous Market Structures}

The final step is to endogenize the number of firms producing each differentiated variety and engaged in either monopolistic or imperfect competition, when there is a fixed cost of creating new firms à la Romer (1990). The dynamic endogenous market structures that emerge are not efficient in general and will be compared to the optimal allocation of resources to characterize the optimal taxation.

The initial stock of capital and number of firms $\left(K_{1}, n_{1}\right)$ are given. The production function (Eqn. 3) is the same as before. Assume that the number of firms/goods follows the law of motion:

$$
n_{t+1}=\left(1-\delta_{n}\right)\left(n_{t}+n_{t}^{e}\right)
$$

where $\delta_{n} \in(0,1)$ is an exogenous exit probability and $n_{t}^{e} \geq 0$ is the endogenous number of entrants in period $t$.

The consumer chooses how much to spend in final goods, how much to invest in stocks of existing and new firms, and how much to invest in physical capital, as already examined in entry models by Ghironi and Melitz (2005), Etro and Colciago (2010), Bilbiie et al. (2012), and others. All this must match the sum of labor and capital income, the profits of the existing firms, and their current value. Expressing the budget constraint of the agent in terms of the intermediate good, the consumer problem becomes:

$$
\begin{gathered}
\max _{\mathbf{C}_{t}, K_{t+1}, L_{t}, x_{t+1}} \mathbb{E}_{i} \sum_{t=1}^{\infty} \beta^{t-1}\left[U\left(\mathbf{C}_{t}, n_{t}\right)-\frac{v L_{t}^{1+\frac{1}{\varphi}}}{1+\frac{1}{\varphi}}\right] \text { s.v. : } \\
K_{t+1}+x_{t+1} \sum_{j=1}^{n_{t+1}} \mathbb{V}_{j t}=K_{t}(1-\delta)+w_{t} L_{t}+r_{t} K_{t}+\sum_{j=1}^{n_{t}}\left[x_{t}\left(\pi_{j t}+\mathbb{V}_{j t}\right)-p_{j t} C_{j t}\right],
\end{gathered}
$$

where $x_{t}$ is the share of (mutual fund investing in) stocks of the firms, $\pi_{j t}$ are the profits/dividends, and $\mathbb{V}_{j t}$ the value of firm $j$ at time $t$, while the other variables are the same as before.

\section{General Equilibrium Dynamics}

The utility maximization problem leads to the same first-order conditions for the consumption of each good $C_{i t}$ as before and the associated inverse demand system for the $n_{t}$ firms active in period $t p_{i t}=U_{i}\left(\mathbf{C}_{t}, n_{t}\right) E_{t}\left[\sum_{j=1}^{n_{t}} C_{j t} U_{j}\left(\mathbf{C}_{t}, n_{t}\right)\right]^{-1}$. This allows one to characterize in each period the monopolistic competition equilibrium where firms take as given the marginal utility of income as well as the number of competitors. Taking into account the exact demand system one can also characterize competition in prices and in quantities (see Bertoletti and Etro 2016, Prop. 1-3). In particular, under monopolistic, Bertrand and Cournot competition, I obtain the respective prices: 


$$
p_{t}=\frac{1}{1-\epsilon\left(C_{t}, n_{t}\right)}, \quad p_{t}^{B}=\frac{\epsilon\left(C_{t}, n_{t}\right)+n_{t}-1}{\left(n_{t}-1\right)\left[1-\epsilon\left(C_{t}, n_{t}\right)\right]}, p_{t}^{C}=\frac{n_{t}}{\left(n_{t}-1\right)\left[1-\epsilon\left(C_{t}, n_{t}\right)\right]}
$$

with profits:

$$
\pi_{t}=\frac{\epsilon\left(C_{t}, n_{t}\right) C_{t}}{1-\epsilon\left(C_{t}, n_{t}\right)}, \pi_{t}^{B}=\frac{n_{t} \epsilon\left(C_{t}, n_{t}\right) C_{t}}{\left(n_{t}-1\right)\left[1-\epsilon\left(C_{t}, n_{t}\right)\right]}, \pi_{t}^{C}=\frac{\left[1+\left(n_{t}-1\right) \epsilon\left(C_{t}, n_{t}\right)\right] C_{t}}{\left(n_{t}-1\right)\left[1-\epsilon\left(C_{t}, n_{t}\right)\right]}
$$

which I assume increasing in individual production/consumption $C_{t}$.

Denoting the generic price as $p\left(C_{t}, n_{t}\right)$, the FOCs for $K_{t+1}$ and $L_{t}$ deliver the modified Euler equation and the labor supply equation as natural extensions of earlier results:

$$
\begin{aligned}
\frac{U_{i}\left(C_{t}, n_{t}\right)}{p\left(C_{t}, n_{t}\right)} & =\beta \mathbb{E}\left\{R_{t+1} \frac{U_{i}\left(C_{t+1}, n_{t+1}\right)}{p\left(C_{t+1}, n_{t+1}\right)}\right\} \\
L_{t} & =\left[\frac{w_{t}}{v} \frac{U_{i}\left(C_{t}, n_{t}\right)}{p\left(C_{t}, n_{t}\right)}\right]^{\varphi}
\end{aligned}
$$

Assume that entry requires a sunk cost $F_{t}$ in units of intermediate good at time $t$. I will leave unspecified the dynamics of the fixed cost $F_{t}$, assuming only that this is low enough to allow entry around the steady state. The reason is that the exogenous process determining the fixed costs will not affect the optimal tax rules around the steady state (even if the business cycle properties of the model do, of course, depend on the nature of the entry costs). Free entry requires that in every moment the number of entrants is such that the value of firms equates the fixed entry cost or zero, if the fixed costs are higher than the value of new firms.

To investigate how many firms enter in the market, I first need to derive the value of the firms, which is the present discounted value of their expected profits. The new FOC of the consumer is the one for $x_{t+1}$ :

$$
\lambda_{t} \mathbb{V}_{t}\left(n_{t}+n_{t}^{e}\right)=\beta \mathbb{E}\left\{\lambda_{t+1}\left(\pi_{t+1}+\mathbb{V}_{t+1}\right) n_{t+1}\right\}
$$

Using the equation of motion for the number of firms and the modified Euler equation, this provides a standard recursive asset pricing formula for $\mathbb{V}_{t}$ :

$$
\mathbb{V}_{t}=\beta\left(1-\delta_{n}\right) \mathbb{E}\left\{\frac{U_{i}\left(C_{t+1}, n_{t+1}\right)}{U_{i}\left(C_{t}, n_{t}\right)} \frac{p\left(C_{t}, n_{t}\right)}{p\left(C_{t+1}, n_{t+1}\right)}\left(\pi_{t+1}+\mathbb{V}_{t+1}\right)\right\}
$$

If the initial conditions are such that investing in capital accumulation provides a higher return than creating new firms (namely, if initially the stock of capital is low, the number of goods is relatively high and the entry cost is high enough), all investment is initially in capital and the number of goods decreases according to $n_{t+1}=\left(1-\delta_{n}\right) n_{t}$, while output and consumption in each good must increase gradually. If, instead, investing in capital accumulation provides initially a lower return (namely if the stock of capital is high and the number of goods relatively low), all investment is initially in business creation and the stock of capital decreases according to $K_{t+1}=(1-\delta) K_{t}$. The equilibrium interest rate decreases in both regimes but none of them is compatible with a steady state equilibrium with positive consumption. Therefore, both these regimes must end when the returns of both forms of investment are equalized: this outcome is reached in finite time and after that savings start being allocated between both forms of 
investment along a path, where both the stock of capital and the number of firms increase toward their steady state values.

In what follows, I will focus on the neighborhood of the steady state where both entry and capital investment occur in each period. Accordingly, the free entry condition $\mathbb{V}_{t}=F_{t}$ and the general expression for symmetric profits $\pi_{t}=\left[p\left(C_{t}, n_{t}\right)-1\right] C_{t}$ allow me to rewrite the asset pricing equation as follows:

$$
\frac{U_{i}\left(C_{t}, n_{t}\right)}{p\left(C_{t}, n_{t}\right)}=\beta\left(\frac{1-\delta_{n}}{F_{t}}\right) \mathbb{E}\left\{\frac{U_{i}\left(C_{t+1}, n_{t+1}\right)}{p\left(C_{t+1}, n_{t+1}\right)}\left[C_{t+1}\left[p\left(C_{t+1}, n_{t+1}\right)-1\right]+F_{t+1}\right]\right\}
$$

Imposing market clearing in equilibrium with $x_{t}=1, V_{t}=F_{t}, w_{t}=A_{t} F_{L}\left(K_{t}, L_{t}\right)$, and $r_{t}=A_{t} F_{K}\left(K_{t}, L_{t}\right)$, the resource constraint becomes:

$$
K_{t+1}-K_{t}(1-\delta)+n_{t}^{e} F_{t}=A_{t} F\left(K_{t}, L_{t}\right)-n_{t} C_{t},
$$

which can be solved for the number of new firms $n_{t}^{e}$ and replaced in the equation of motion for the total number of firms (Eqn. 40). This is what I do to summarize the equilibrium around a steady state as follows:

Proposition 3. In a dynamic model with general intratemporal preferences and imperfect competition between an endogenous number of firms the equilibrium satisfies:

$$
\begin{gathered}
\frac{U_{i}\left(C_{t}, n_{t}\right)}{p\left(C_{t}, n_{t}\right)}=\beta \mathbb{E}\left\{\frac{U_{i}\left(C_{t+1}, n_{t+1}\right)}{p\left(C_{t+1}, n_{t+1}\right)}\left[1+A_{t} F_{K}\left(K_{t+1}, L_{t+1}\right)-\delta\right]\right\} \\
=\beta\left(\frac{1-\delta_{n}}{F_{t}}\right) \mathbb{E}\left\{\frac{U_{i}\left(C_{t+1}, n_{t+1}\right)}{p\left(C_{t+1}, n_{t+1}\right)}\left[C_{t+1}\left[p\left(C_{t+1}, n_{t+1}\right)-1\right]+F_{t+1}\right]\right\} \\
L_{t}=\left[\frac{A_{t} F_{L}\left(K_{t}, L_{t}\right) U_{i}\left(C_{t}, n_{t}\right)}{v p\left(C_{t}, n_{t}\right)}\right]^{\varphi} \\
n_{t+1}=\left(1-\delta_{n}\right)\left[n_{t}+\frac{A_{t} F\left(K_{t}, L_{t}\right)-n_{t} C_{t}-K_{t+1}+K_{t}(1-\delta)}{F_{t}}\right]
\end{gathered}
$$

around the steady state, where $p(C, n)$ is the relevant price function.

The first equation is the modified Euler equation, the second the endogenous entry equation, the third the labor supply, and the last the equation of motion for the number of firms. They govern the evolution of the stock of capital $K_{t}$, labor supply $L_{t}$, consumption/production of each good $C_{t}$, and number of firms $n_{t}$. It is immediate to reduce the system to a three-dimensional system for $\left(C_{t}, K_{t}, n_{t}\right)$ with labor supply determined residually. Moreover, equating the right hand sides of the Euler and endogenous entry conditions, which represent the expected return rates, respectively, on investment in capital and in business creation, one can express consumption in each period $t$ as a function of the stock of capital and the number of firms in the same period, or to reduce the equilibrium system to a bi-dimensional system for $\left(C_{t}, n_{t}\right)$. Finally, as the profit function is increasing in consumption, I obtain that the production/consumption of each good declines over time while capital accumulates (and the equilibrium return rate declines). ${ }^{14}$ I now move to the welfare analysis and derive the optimal tax rules, which hold around any well defined steady state.

\footnotetext{
${ }^{14}$ Stability holds under standard parametrization. However, the model can also deliver i) cycling behavior of the number of firms (under high exit rates or a low discount factor), or ii) unbounded growth of the number of firms (when the return on business creation is constant à la Romer 1986, 1990).
} 


\section{Optimal Dynamic Market Structures}

For any decentralized equilibrium path characterized in the earlier section, I can make a comparison with the social planner solution and determine the tax system that restores the latter. Replacing the equation of motion for the number of firms (Eqn. 40) in the resource constraint (Eqn. 46) and solving for the symmetric consumption of each good $C_{t}$, express the symmetric intratemporal utility $U\left(C_{t}, n_{t}\right)$ and state the social planner problem as follows:

$$
\max _{\substack{K_{t+1}, L_{t}, n_{t+1}}} \mathbb{E}^{\infty} \sum_{t=1}^{\infty} \beta^{t-1}\left[U\left(\frac{A_{t} F\left(K_{t}, L_{t}\right)-K_{t+1}+K_{t}(1-\delta)-\frac{n_{t+1} F_{t}}{1-\delta_{n}}}{n_{t}}+F_{t}, n_{t}\right)-\frac{v L_{t}^{1+\frac{1}{\varphi}}}{1+\frac{1}{\varphi}}\right] .
$$

Using the properties of the symmetric functions, the FOCs for $K_{t+1}, L_{t}$, and $n_{t+1}$ can be rearranged as:

$$
\begin{gathered}
U_{i}\left(C_{t}^{*}, n_{t}^{*}\right)=\beta \mathbb{E}\left\{\left[1+A_{t+1} F_{K}\left(K_{t+1}^{*}, L_{t+1}^{*}\right)-\delta\right] U_{i}\left(C_{t+1}^{*}, n_{t+1}^{*}\right)\right\} \\
L_{t}^{*}=\left[\frac{A_{t} F_{L}\left(K_{t}^{*}, L_{t}^{*}\right) U_{i}\left(C_{t}^{*}, n_{t}^{*}\right)}{v}\right]^{\varphi} \\
U_{i}\left(C_{t}^{*}, n_{t}^{*}\right) F_{t}=\beta\left(1-\delta_{n}\right) \mathbb{E}\left\{U_{n}\left(C_{t+1}^{*}, n_{t+1}^{*}\right)-U_{i}\left(C_{t+1}^{*}, n_{t+1}^{*}\right)\left(C_{t+1}^{*}-F_{t+1}\right)\right\},
\end{gathered}
$$

where $U_{n}(C, n)=\partial U(C, n) / \partial n$ is defined with a slight abuse of notation. These optimality conditions extend to a dynamic context the analysis of optimal market structures presented in Bertoletti and Etro (2016) for a static context. The optimal number of firms derives from the trade-off between the costs of producing new varieties and the benefits of enjoying them (in the future) net of the reduction of consumption (needed to invest in replacing varieties lost over time). This trade-off depends on the elasticities of the welfare function $U(C, n)$ with respect to consumption and the number of goods:

$$
\psi^{C}(C, n) \equiv \frac{U_{i}(C, n) C}{U(C, n)} \text { and } \psi^{n}(C, n) \equiv \frac{U_{n}(C, n) n}{U(C, n)} .
$$

Indeed, the last FOC can be rearranged as follows:

$$
U_{i}\left(C_{t}^{*}, n_{t}^{*}\right)=\beta\left(\frac{1-\delta_{n}}{F_{t}}\right) \mathbb{E}\left\{U_{i}\left(C_{t+1}^{*}, n_{t+1}^{*}\right)\left[C_{t+1}^{*}\left[\frac{\psi^{n}\left(C_{t+1}^{*}, n_{t+1}^{*}\right)}{\psi^{C}\left(C_{t+1}^{*}, n_{t+1}^{*}\right)}-1\right]+F_{t+1}\right]\right\}
$$

whose right-hand side emphasizes the social return from creating new varieties, which is typically different from the private return that depends on expected rate of profits.

\section{Optimal Taxes with Monopolistic Competition}

The comparison between the optimality conditions and the decentralized free entry conditions augmented with taxes leads to the optimal corrective taxation. This requires three time-changing taxes: in each period $t$, the labor subsidy turns the effective wage into $\left(1+\tau_{t}^{L}\right) w_{t}$, the capital income tax turns the effective gross return rate on capital investment into $\left(1-\tau_{t}^{K}\right) R_{t}$, and I need to introduce 
a tax on profits/dividends $\tau_{t}^{D}$, which turns the net profits/dividends into $\left(1-\tau_{t}^{D}\right) \pi_{t}$. Amending the equilibrium equations under monopolistic competition to include these taxes and equating them with the social optimum equations derived above obtains:

PROPOSITION 4. In a dynamic model with general intratemporal preferences and monopolistic competition between an endogenous number of firms the optimal taxes around the steady state are:

$$
\begin{gathered}
\tau_{t}^{L}=\frac{\epsilon\left(C_{t}, n_{t}\right)}{1-\epsilon\left(C_{t}, n_{t}\right)}, \\
\tau_{t}^{K}=\frac{\epsilon\left(C_{t-1}, n_{t-1}\right)-\epsilon\left(C_{t}, n_{t}\right)}{1-\epsilon\left(C_{t}, n_{t}\right)}, \\
\tau_{t}^{D}=\frac{1-\left[1-\epsilon\left(C_{t}, n_{t}\right)\right] \frac{\psi^{n}\left(C_{t}, n_{t}\right)}{\psi^{C}\left(C_{t}, n_{t}\right)}}{\epsilon\left(C_{t}, n_{t}\right)},
\end{gathered}
$$

where $\psi^{n}(C, n)$ and $\psi^{n}(C, n)$ are the elasticities of utility with respect to number of goods and aggregate consumption.

The relative simplicity of this optimal tax system relies on the fact that the tax rates can be directly computed as (nonlinear) functions of the number of firms active in each period and the production level of each firm. Some remarks are in order. First, the traditional case of a constant labor subsidy and a zero capital income tax emerges only under preferences that deliver a symmetric Morishima elasticity independent from consumption and from the number of goods. A well-known case is the one of CES aggregators, but Bertoletti and Etro (2016) have shown that there are other possible cases.

Second, except for these special cases, general preferences generate variable optimal tax rates over the business cycle (for the case of homothetic preferences, see Bilbiie et al. 2016). The general principle is that countercyclical markups require a countercyclical labor subsidy and a positive capital income tax along the growth path toward the steady state. In the long run, however, the optimal capital income tax is zero for any preferences, confirming the traditional result (Chamley 1986) also for the case of endogenous entry.

Third, the optimal tax on profits is aimed at restoring the efficient entry process. The traditional case of a CES aggregator with intratemporal preferences (Eqn. 2) implies $\epsilon(C, n)=1 / \theta$ and $\psi^{n}(C, n) / \psi^{C}(C, n)=\theta /(\theta-1)$; therefore, the optimal profit tax is zero in each period: both entry and capital accumulation are efficient, therefore only labor should be subsidized to restore optimality in the CES case. More generally, however, profit taxation is needed to reach the efficient number of entrants in each period. The underlying principle is that this taxation should be positive if markups are too high. To see what determines whether markups are too high or too low and characterize the optimal taxation, I reexamine earlier examples of preferences.

\section{Quadratic Direct Utility}

I can directly compute the optimal tax system for the example of quadratic preferences (Eqn. 23). The welfare function $U(C, n)=\alpha n C-\frac{\gamma n C^{2}}{2}-\frac{\eta n^{2} C^{2}}{2}$ allows one to compute $\psi^{C}(C, n)$ and $\psi^{n}(C, n)$, and derive the optimal tax rates as:

$$
\tau_{t}^{L}=\frac{C_{t}}{B_{t}}, \tau_{t}^{K}=\frac{\alpha\left(C_{t-1}-C_{t}\right)-C_{t} C_{t-1}\left(n_{t}-n_{t-1}\right)}{B_{t}\left[\alpha-\left(\gamma+\eta n_{t-1}\right) C_{t-1}\right]}, \tau_{t}^{D}=\frac{\alpha \gamma-\alpha \eta n_{t}+\gamma \eta n_{t} C_{t}+\eta^{2} n_{t}^{2} C_{t}}{2 \gamma\left[\alpha-\left(\gamma+\eta n_{t}\right) C_{t}\right]}
$$


where $B_{t} \equiv\left[\alpha-\left(2 \gamma+\eta n_{t}\right) C_{t}\right] / \gamma$. These tax rates depend on both the production/consumption of each good and the number of firms producing these goods, which complicates things compared to the earlier case with a given number of firms. An increase in both the number of goods and the individual production/consumption tends to increase the labor income subsidy and to determine a negative income tax. However, this specification is consistent with both positive or negative values for the optimal capital income and dividend taxes. ${ }^{15}$

\section{Directly Additive Aggregators}

With directly additive aggregators (Eqn. 25), the welfare function $U(n u(C))$ implies that $\psi^{n}(C, n) /$ $\psi^{C}(C, n)=1 / \psi(C)$, where $\psi(C) \equiv u^{\prime}(C) C / u(C)>0$ is the elasticity of the subutility function $u(C)$. Computing the derivative $\psi^{\prime}(C)=\psi(C) \frac{1-\epsilon(C)-\psi(C)}{C}$, rearrange the optimal tax system as follows:

$$
\tau_{t}^{L}=\frac{\epsilon\left(C_{t}\right)}{1-\epsilon\left(C_{t}\right)}, \tau_{t}^{K}=\frac{\epsilon\left(C_{t-1}\right)-\epsilon\left(C_{t}\right)}{1-\epsilon\left(C_{t}\right)} \text {, and } \tau_{t}^{D}=\frac{-C_{t} \psi^{\prime}\left(C_{t}\right)}{\epsilon\left(C_{t}\right) \psi\left(C_{t}\right)^{2}} .
$$

Note that the optimal taxation is independent from the form of the monotonic transformation $U(\cdot)$. The tax rates on the inputs are the same as in the baseline model, while the profit tax is positive if and only if the elasticity of the subutility function is decreasing in consumption. This is a dynamic generalization of the static principle found in Dixit and Stiglitz (1977), for which excess entry occurs in this case. My examples with CARA and translated power subutilities require a positive profit taxation because their elasticities are decreasing in consumption and the decentralized equilibrium features too many firms.

\section{Indirectly Additive Aggregators}

With aggregators represented by an indirectly additive utility (Eqn. 28), the welfare function $U$ $(n v(1 / n C))$ implies $\psi^{n}(C, n) / \psi^{C}(C, n)=1+1 / \eta(1 / n C)$, where $\eta(s)=-v^{\prime}(s) s / v(s)$ is the elasticity of the subutility function $v(s)$. Computing the derivative $\eta^{\prime}(s)=\eta(s) \frac{1-\theta(s)+\eta(s)}{s}$, rearrange the optimal tax system as:

$$
\tau_{t}^{L}=\frac{1}{\theta\left(s_{t}\right)-1}, \quad \tau_{t}^{K}=\frac{\theta\left(s_{t}\right)-\theta\left(s_{t-1}\right)}{\left[\theta\left(s_{t}\right)-1\right] \theta\left(s_{t-1}\right)}, \text { and } \tau_{t}^{D}=\frac{s_{t} \eta^{\prime}\left(s_{t}\right)}{\eta\left(s_{t}\right)^{2}}
$$

where $s_{t}=p_{t} / E_{t}=1 / n_{t} C_{t}$. Such an optimal scheme is related to static results in Bertoletti and Etro (2017), where excess entry occurs if and only if the elasticity of the subutility is increasing in the price. This requires a positive profit taxation in each period to restore the optimal entry process, as in the examples analyzed in the Appendix with linear demand or exponential subutility, whose price elasticities are increasing and excess entry occurs in the decentralized equilibrium.

\section{Homothetic Aggregators}

Finally, consider intratemporal preferences that are homothetic with a welfare function $U[C H$ $(\mathbf{l}, n)]$. It is easy to verify that $\psi^{n}(n) / \psi^{C}(n)$ depends only on the number of goods. Therefore, the optimal taxes change over time in function of the endogenous number of firms only. Two examples will clarify this result.

\footnotetext{
${ }^{15}$ For instance, for $\eta$ low enough I obtain a positive dividend taxation.
} 
Feenstra (2003) has analyzed homothetic preferences based on a translog expenditure function, which implies $\epsilon(n)=\frac{1}{1+\sigma n}$ and $\psi^{n}(C, n) / \psi^{C}(C, n)=1+1 / 2 \sigma n$, where $\sigma>0$ is a parameter related to substitutability between goods. This generates countercyclical prices and allows one to compute the optimal taxes as:

$$
\tau_{t}^{L}=\frac{1}{\sigma n_{t}}, \quad \tau_{t}^{K}=\frac{n_{t}-n_{t-1}}{n_{t}\left(1+\sigma n_{t-1}\right)}, \text { and } \tau^{D}=\frac{1}{2}
$$

which deliver, during the entry process, a decreasing labor subsidy, a positive and decreasing capital income tax, and a constant tax on dividends. These results are consistent with those of Bilbiie et al. (2016).

The implicitly additive aggregators of Kimball (1995) belong to a more general class of preferences originally introduced by Hanoch (1974). Consider a direct utility represented by a homogenous aggregator $H(\mathbf{C}, n)$, which is implicitly defined by:

$$
\sum_{j=1}^{n} u\left(\frac{C_{j}}{H(\mathbf{C}, n)}\right)=1,
$$

where the function $u(x)$ has the same properties of a direct subutility. Using symmetry and homogeneity, $u(C / H(C \mathbf{l}, n)) \equiv u(x(n))=1 / n$, where $x(n) \equiv H(\mathbf{l}, n)^{-1}$ is a decreasing function of the number of goods. For instance, in the CES case, $u(x)=x^{\frac{\theta-1}{\theta}}$ and $x(n)=1 / n$, and additivity becomes explicit.

Under flexible prices I can easily characterize the equilibrium markups in each period. By duality principles, the intratemporal problem can be seen as minimizing spending $E=\sum_{j=1}^{n} p_{j} C_{j}$ with respect to each consumption level under the utility constraint (Eqn. 52). This provides the inverse demand:

$$
p_{j}=u^{\prime}\left(\frac{C_{j}}{H(\mathbf{C}, n)}\right) \frac{\mu}{H(\mathbf{C}, n)}
$$

where $\mu$ is the Lagrange multiplier. Applying Equation 15, I can compute the symmetric elasticity $\epsilon(n)=\frac{-u^{\prime}(x(n)) x(n)}{u^{\prime}(x(n))}$. Notice that this can be either increasing or decreasing in the number of goods, so the equilibrium prices can either increase or decrease with entry.

Finally, under symmetry the homogenous aggregator $H$ is implicitly defined by $n u(C / H)=1$, which provides $\psi^{n}(C, n) / \psi^{C}(C, n)=1 / \psi(x(n))$, where the function $\psi(x)$ is always defined as the elasticity of $u(x)$. Direct computation gives $\psi^{\prime}(x)=\psi(x) \frac{1-\epsilon(x)-\psi(x)}{x}$ and the optimal tax system can be expressed as follows:

$$
\tau_{t}^{L}=\frac{\epsilon\left(n_{t}\right)}{1-\epsilon\left(n_{t}\right)}, \tau_{t}^{K}=\frac{\epsilon\left(n_{t-1}\right)-\epsilon\left(n_{t}\right)}{1-\epsilon\left(n_{t}\right)}, \text { and } \tau_{t}^{D}=\frac{-x\left(n_{t}\right) \psi^{\prime}\left(x\left(n_{t}\right)\right)}{\epsilon\left(n_{t}\right) \psi\left(x\left(n_{t}\right)\right)^{2}}
$$

The optimal labor subsidy is countercyclical and the optimal capital tax is positive if and only if the markups are decreasing in the number of firms. Instead, the dividend tax is positive if and only if the elasticity of the $u(\cdot)$ function is decreasing, and in general it depends on the number of firms. It would now be simple to replicate the analysis for the family of homothetic preferences with 
an indirect utility that is implicitly additive (once again CES preferences belong to this family and to the one analyzed in the text).

In principle, more general additivity, introduced in section 2, could be analyzed similarly once the three relevant elasticities are expressed in terms of consumption and number of firms.

\section{Optimal Taxes with Bertrand and Cournot Competition}

Dynamic endogenous market structures in the presence of strategic interactions can be analyzed in a similar way. The equilibrium in Proposition 3 must incorporate the prices under either Bertrand or Cournot competition from Equation 41. The case of log-CES preferences is similar to the model in Etro and Colciago (2010), but I can now explore any other microfoundation of the demand side. The dynamic properties of the equilibrium are similar to the case with monopolistic competition except for the procompetitive effects due to the strategic interactions. A temporary expansionary shock generates two parallel and interacting mechanisms: on the supply side the boom attracts entry of new firms, which tends to strengthen competition and depress markups, while on the demand side the boom changes the demand elasticity with an ambiguous impact on markups. The propagation mechanism is once again much richer compared to the CES environment.

I can characterize the optimal taxation for this environment matching equilibrium and efficiency conditions. In a dynamic model with general intratemporal preferences and Cournot competition between an endogenous number of firms, the optimal taxes around the steady state can be computed, after tedious computations, as follows:

$$
\begin{gathered}
\tau_{t}^{L C}=\frac{\frac{1}{n_{t}-1}+\epsilon\left(C_{t}, n_{t}\right)}{1-\epsilon\left(C_{t}, n_{t}\right)}, \\
\tau_{t}^{K C}=\frac{\epsilon\left(C_{t-1}, n_{t-1}\right)-\epsilon\left(C_{t}, n_{t}\right)}{1-\epsilon\left(C_{t}, n_{t}\right)},
\end{gathered}
$$

and

$$
\tau_{t}^{D C}=\frac{n_{t}-\left(n_{t}-1\right)\left[1-\epsilon\left(C_{t}, n_{t}\right)\right] \frac{\psi^{n}\left(C_{t}, n_{t}\right)}{\psi^{C}\left(C_{t}, n_{t}\right)}}{\left[1+\left(n_{t}-1\right) \epsilon\left(C_{t}, n_{t}\right)\right]}
$$

In the case of CES aggregators, I obtain a very simple optimal tax system, with a zero capital income tax, a countercyclical labor subsidy $\tau_{t}^{L C}=\frac{\theta+n_{t}-1}{(\theta-1)\left(n_{t}-1\right)}$, and a countercyclical profit tax $\tau_{t}^{D C}=\frac{\theta}{\theta+n_{t}-1}$. The latter is consistent with a long-run optimal tax obtained by Colciago (2016) under an equivalent assumption on the entry costs. ${ }^{16}$ Notice that with homogenous goods $(\theta \rightarrow \infty)$, the case analyzed in Colciago and Etro (2010), there is $\tau_{t}^{L C} \rightarrow \frac{1}{n_{t}-1}$ and $\tau_{t}^{D C} \rightarrow 1$ because it is convenient to disincentivize the creation of new firms (there are no gains from variety) and incentivize individual production (as long as strategic interactions between a small number of firms restrict production). In general, the optimal profit tax is positive because imperfect competition attracts more entry than monopolistic competition (which generates the efficient number of firms under

\footnotetext{
${ }^{16}$ In reality, Colciago (2016) assumes a fixed cost in units of labor, and has no capital. This is equivalent to assuming a fixed cost in units of an intermediate good produced with labor only.
} 
CES preferences). Departing from the CES case, the profit tax can be either positive or negative, but it must be higher than with monopolistic competition because imperfect competition tends to deliver higher markups.

In the case of Bertrand competition between an endogenous number of firms, the optimal taxes around the steady state can be derived as:

$$
\begin{gathered}
\tau_{t}^{L B}=\frac{\epsilon\left(C_{t}, n_{t}\right)}{\left(1-\frac{1}{n_{t}}\right)\left[1-\epsilon\left(C_{t}, n_{t}\right)\right]}, \\
\tau_{t}^{K B}=\frac{\epsilon\left(C_{t-1}, n_{t-1}\right)-\epsilon\left(C_{t}, n_{t}\right)}{\left[1-\epsilon\left(C_{t}, n_{t}\right)\right]\left[1-\frac{1-\epsilon\left(C_{t-1}, n_{t-1}\right)}{n_{t}}\right]},
\end{gathered}
$$

and

$$
\tau_{t}^{D B}=\frac{1}{n_{t}}+\frac{\left(n_{t}-1\right)\left[1-\left[1-\epsilon\left(C_{t}, n_{t}\right)\right] \frac{\psi^{n}\left(C_{t}, n_{t}\right)}{\psi^{C}\left(C_{t}, n_{t}\right)}\right]}{n_{t} \epsilon\left(C_{t}, n_{t}\right)} .
$$

Again, with CES preferences, I obtain a very simple optimal tax system, with a zero capital income tax, a labor subsidy $\tau_{t}^{L B}=\frac{n_{t}}{(\theta-1)\left(n_{t}-1\right)}$ decreasing with the number of firms and the substitutability between goods, and a profit tax which is independent from substitutability and inversely proportional to the number of firms, according to the simple rule $\tau_{t}^{D B}=\frac{1}{n_{t}}$, which is again consistent with Colciago (2016). In general, strategic interactions increase the markups relative to monopolistic competition, therefore the optimal fiscal wedges are, ceteris paribus, higher.

\section{Conclusions}

Departing from perfect competition and CES preferences, flexible price DSGE models deliver new channels of propagation of the shocks and new inefficiencies that operate through changes in the endogenous markups. Remarkably, these changes depend crucially on the properties of preferences, restoring a novel role for the demand side in determining the propagation of the business cycle and the properties of optimal fiscal policy. I have analyzed these dynamic models and evaluated the optimal taxation that restores the first best allocation of resources through taxes on labor income, capital income, and dividends.

This framework could be also applied to examine Ramsey policies of optimal distortionary taxation (in the absence of lump sum taxes), as done by Colciago (2016) only for the case of CES preferences: optimal taxation should then account for the standard principle of lower taxation on more elastic demand functions and markup synchronization. Nonhomotheticity could also be exploited in analysis of structural transformation (Matsuyama 2017). One could introduce price frictions (in the intermediate good sector) for the analysis of monetary shocks in a New-Keynesian style. Finally, one could study shocks and policies in an open economy framework (see Ghironi and Melitz 2005 with CES preferences): an attempt in this direction is in Cavallari and Etro (2017). A flourishing literature in international trade has been recently departing from CES preferences to investigate the main classes of preferences emphasized here with heterogeneous firms. In particular, this is the case of quadratic preferences (Melitz and Ottaviano 2008), directly additive preferences (Arkolakis et al., 2015), indirectly additive preferences (Bertoletti et al. 2018), some versions of 
homothetic preferences (Feenstra 2018), and GAS preferences (Bertoletti and Etro 2018). A contamination between these literatures could be fruitful.

My ultimate objective would be to provide a general microfoundation of DSGE models to expand their ability to replicate empirical findings on international business cycles (for some related insights see Cavallari and Etro 2017 or Anderson et al. 2018), incorporate realistic imperfections in the labor and credit markets (see La Croce and Rossi 2014 and Etro 2016b), and be used for the analysis of fiscal and monetary policy (see Ghironi 2018). I believe that many of the limits of the standard macroeconomic framework are deeply linked with the ubiquity of CES preferences and exogenous market structures, which prevent me from modeling realistic imperfections in the goods market and fully understanding interactions between demand and supply at the aggregate level.

\section{Appendix: Euler Equations with Indirectly Additive Preferences}

A general class of preferences recently introduced in the static analysis of monopolistic competition is characterized by an indirect utility that is additive. Here I will analyze the equilibrium of the dynamic model for a given number of goods when intratemporal preferences satisfy indirect additivity.

Assume that the intratemporal indirect utility in Equation 10 is additively separable as in:

$$
V\left(\frac{\mathbf{p}}{E}\right)=U\left(\sum_{j=1}^{n} v\left(\frac{p_{j}}{E}\right)\right),
$$

where $v(s)$ is decreasing and convex in the price-expenditure ratio $s=p / E$ and $U(\cdot)$ is a monotonic transformation.

In this case, I can reformulate easily the derivation of the decentralized equilibrium. The demand for each good $i$ in period $t$ derives from the Roy's identity, and the corresponding profits are:

$$
\pi_{i t}=\frac{\left(p_{i t}-1\right) v^{\prime}\left(\frac{p_{i t}}{E_{t}}\right) E_{t}}{\sum_{j=1}^{n} v^{\prime}\left(\frac{p_{j t}}{E_{t}}\right) p_{j t}},
$$

whose denominator is directly related to the marginal utility of income and is taken as given under monopolistic competition. The monopolistic price satisfies:

$$
p_{t}=\frac{\theta\left(p_{t} / E_{t}\right)}{\theta\left(p_{t} / E_{t}\right)-1},
$$

where $\theta(s) \equiv-v^{\prime \prime}(s) s / v^{\prime}(s)$ is the demand elasticity in function of the price-expenditure ratio. Symmetry implies $E_{t}=n p_{t} C_{t}$; therefore the price can be seen as a function of the product of consumption and number of firms through $\theta(1 / n C)$, and it is increasing in the consumption level if $\theta^{\prime}(s)>0$. Instead, monopolistic competition prices are countercyclical if $\theta^{\prime}(s)<0$.

In each period, since the direct demand of each good is already implicit in the specification of preferences, the consumer chooses only total spending $E_{t}$ and labor supply $L_{t}$ to maximize intertemporal utility (Eqn. 10) under the resource constraint. The problem:

$$
\begin{gathered}
\max _{E_{t+1}, L_{t}} \mathbb{U}=\mathbb{E} \sum_{t=1}^{\infty} \beta^{t-1}\left[U\left(\sum_{j=1}^{n} v\left(\frac{p_{j t}}{E_{t}}\right)\right)-\frac{v L_{t}^{1+\frac{1}{\varphi}}}{1+\frac{1}{\varphi}}\right] \\
K_{t+1}=K_{t}(1-\delta)+w_{t} L_{t}+r_{t} K_{t}+\Pi_{t}-E_{t}
\end{gathered}
$$

leads to the Euler condition: ${ }^{17}$

\footnotetext{
${ }^{17}$ A similar result is obtained by Etro (2016b) to analyze a Ramsey model of consumption growth, and used also by Boucekkine et al. (2017) for an interesting analysis of endogenous growth.
} 


$$
\frac{-v^{\prime}\left(\frac{p_{t}}{E_{t}}\right) U^{\prime}\left[n v\left(\frac{p_{t}}{E_{t}}\right)\right] p_{t}}{E_{t}^{2}}=\beta \mathbb{E}\left\{\frac{-v^{\prime}\left(\frac{p_{t+1}}{E_{t+1}}\right) U^{\prime}\left[n v\left(\frac{p_{t+1}}{E_{t+1}}\right)\right] p_{t+1} R_{t+1}}{E_{t+1}^{2}}\right\} .
$$

This is a particular case of the general framework once I recognize that in a symmetric equilibrium $p_{t} / E_{t}=1 / n C_{t}$.

As a well-behaved indirect utility function is increasing in income but not necessarily concave, the transformation $U$ must insure enough concavity for the equilibrium to be well defined. For instance, if $U$ is linear, one can verify that this is the case if and only if $\theta(s) \in(1,2)$, which is quite restrictive for the analysis of monopolistic competition. ${ }^{18}$ Therefore, in what follows I focus on the case of a logarithmic transformation, with $U(\cdot)=\log (\cdot)$, whose concavity insures saddle-path stability under more general conditions.

Defining $\eta(s)=-v^{\prime}(s) s / v(s)$ as the elasticity of the subutility, $\eta(p / E)=\eta(1 / n C)$ and $\epsilon(C, n)=1 / \theta(1 / n C)$. This allows me to rewrite the modified Euler condition as a particular case of the general model:

$$
\frac{\eta\left(\frac{1}{n C_{t}}\right)}{C_{t}}\left[1-\theta\left(\frac{1}{n C_{t}}\right)^{-1}\right]=\beta \mathbb{E}\left\{\frac{R_{t+1} \eta\left(\frac{1}{n C+1 t}\right)}{C_{t+1}}\left[1-\theta\left(\frac{1}{n C_{t+1}}\right)^{-1}\right]\right\} .
$$

With CES preferences both elasticities are constant and I am back to the same results of perfect competition, as under the log-CES specification (Eqn. 2). When the demand elasticity is variable, instead, market power has bite and affects the business cycle properties of the model.

This class of preferences can be easily analyzed in macroeconomic models. As an example, consider the case of translated power preferences with subutility (Etro 2016a):

$$
v(s)=(s-\bar{s})^{1-\theta},
$$

for a minimum normalized price $\bar{s}>0$. This specification delivers the elasticities $\theta(s)=\theta s /(s-\bar{s})$ and $\eta(s)=(\theta-1) s /(s-\bar{s})$, which are decreasing in $s$. Therefore the elasticity $€(C, n)=\frac{1-\bar{s} n C}{\theta}$ is linearly decreasing in consumption under the regularity condition $C_{t}<1 / \bar{s} n$. The Euler equation can be derived as:

$$
\frac{1}{\left(1-\bar{s} n C_{t}\right) p_{t} C_{t}}=\beta \mathbb{E}\left\{\frac{R_{t+1}}{\left(1-\bar{s} n C_{t+1}\right) p_{t+1} C_{t+1}}\right\},
$$

where under perfect competition I should set $p_{t}=1$ and under monopolistic competition I should set:

$$
p_{t}=\frac{\theta}{\theta-1+\bar{s} n C_{t}} .
$$

Note that the markup is countercyclical, therefore market power tends to enhance the propagation of shocks. Accordingly, optimal taxation requires a countercyclical labor income subsidy and a positive tax on capital income on the growth path.

Consider the preferences used by Bertoletti et al. (2018) in a static analysis of monopolistic competition, with subutility:

$$
v(s)=\frac{(a-s)^{1+\gamma}}{1+\gamma},
$$

where $a>0$ represents the maximum willingness to pay (demand is 0 for normalized prices above this level) and $\gamma>0$ parametrizes the demand elasticity. In general, the demand is a power function of a linear demand, with elasticities $\theta(s)=\gamma s /(a-s)$ and $\eta(s)=(1+\gamma) s /(a-s)$, which are increasing in $s$. Therefore, the elasticity $€(C, n)=\frac{a n C-1}{\gamma}$ is linearly increasing in consumption under the regularity condition $1<a n C_{t}<1+\gamma$. The Euler equation can be derived as:

$$
\frac{1}{\left(a n C_{t}-1\right) p_{t} C_{t}}=\beta \mathbb{E}\left\{\frac{R_{t+1}}{\left(a n C_{t+1}-1\right) p_{t+1} C_{t+1}}\right\},
$$

\footnotetext{
${ }^{18}$ I am thankful to Paolo Bertoletti for insightful discussions on this condition and on the concept of intertemporal elasticity of substitution. On the latter, a useful reading is Browning and Crossley (2000).
} 
where under perfect competition I should set $p_{t}=1$ and under monopolistic competition:

$$
p_{t}=\frac{\gamma}{1+\gamma-a n C_{t}} .
$$

Note that the markup is procyclical, therefore, market power tends to enhance consumption smoothing compared to perfect competition. Optimal taxation requires a procyclical labor income subsidy and a negative tax on capital income on the growth path.

As a last example, consider the exponential indirect subutility:

$$
v(s)=e^{-b s}
$$

with $b>0$ parametrizing the semi-elasticity of demand, which is loglinear in this case. Notice that $\theta(s)=\eta(s)=b s$, which is increasing in $s$, therefore, $\epsilon(C, n)=\frac{n C}{b}$ is increasing in individual consumption. Under monopolistic competition, the equilibrium price is:

$$
p_{t}=\frac{b}{b-n C_{t}}
$$

which is procyclical under the regularity condition $C_{t}<b / n$. The Euler condition becomes:

$$
\frac{1}{C_{t}^{2} p_{t}}=\beta \mathbb{E}\left\{\frac{R_{t+1}}{C_{t+1}^{2} p_{t+1}}\right\} .
$$

Under perfect competition there would be a very simple variation of the traditional Euler condition. However, the modified Euler equation under monopolistic competition depends on demand elasticity through the parameter $b$, as well as on the number of goods. Also in this case market power dampens the propagation of shocks compared to perfect competition, and the first best is restored subsidizing both labor and capital income when consumption grows.

\section{Acknowledgments}

I am extremely grateful to Andrea Colciago, Thomas Crossley, Fabio Ghironi, Paolo Bertoletti, Lorenza Rossi, and especially Lilia Cavallari, as well as to seminar participants at the Dutch National Bank, the University of Essex, the RMIT University (Ho Chi Min), the University of Malaya (Kuala Lumpur), and the 2016 Annual Conference of the Association of Italian Economists held at Bocconi University.

\section{References}

Anderson, Eric, Sergio Rebelo and Arlene Wong. 2018. Markups across space and time, NBER WP No. 24434.

Arkolakis, Costas, and Monica Morlacco. Variable demand elasticity, markups, and pass-through. Yale University: Unpublished Paper, 2017.

Arkolakis, Costas, Arnaud Costinot, Dave Donaldson and Andres Rodríguez-Clare. 2015. The elusive pro-competitive effects of trade, NBER Working Paper No. 21370.

Benassy, Jean Paul. 1997. Taste for variety and optimum production patterns in monopolistic competition. Economics Letters 52(1):41-7.

Bertoletti, Paolo, and Federico Etro. Monopolistic competition, as you like it (Unpublished paper). University of Venice, Venice, 2015.

Bertoletti, Paolo, and Federico Etro. 2016. Preferences, entry and market structure. RAND Journal of Economics 47(4): 792-821.

Bertoletti, Paolo, and Federico Etro. 2017. Monopolistic competition when income matters. Economic Journal 127(603): $1217-43$.

Bertoletti, Paolo and Federico Etro. 2018. Monopolistic competition with GAS preferences. Unpublished paper, University of Pavia.

Bertoletti, Paolo, Federico Etro, and Ina Simonovska. 2018. International trade with indirect additivity. American Economic Journal: Microeconomics 10(2):1-57. 
Bertoletti, Paolo, Eilen Fumagalli, and Chiara Poletti. 2017. Price-increasing monopolistic competition? The case of IES preferences. Research in Economics 71(4):653-62.

Bilbiie, Florin, Fabio Ghironi, and Marc Melitz. 2008. Monetary policy and business cycles with endogenous entry and product variety. In NBER macroeconomic annual 2007, edited by D. Acemoglu, K. Rogoff and M. Woodford. Cambridge, 299-353.

Bilbiie, Florin, Fabio Ghironi, and Marc Melitz. 2012. Endogenous entry, product variety, and business cycles. Journal of Political Economy 120(2):304-45.

Bilbiie, Florin, Fabio Ghironi and Marc Melitz. 2016. Monopoly power and endogenous variety: Distortions and remedies, CEPR Discussion Paper No. 11294.

Bils, Mark. 1987. The cyclical behavior of marginal cost and price. American Economic Review 77(5):838-55.

Blackorby, Charles, and Robert Russell. 1981. The Morishima elasticity of substitution: Symmetry, constancy, separability, and its relationship to the hicks and Allen elasticities. Review of Economic Studies 48:147-58.

Blanchard, Olivier, and Nobuhiro Kiyotaki. 1987. Monopolistic competition and the effects of aggregate demand. American Economic Review 77(4):647-66.

Boucekkine, Raouf, Hélène Latzer, and Mathieu Parenti. 2017. Variable markups in the long-run: A generalization of preferences in growth models. Journal of Mathematical Economics 68(C):80-6.

Browning, Martin, and Thomas F. Crossley. 2000. Luxuries are easier to postpone: A proof. Journal of Political Economy 108(5):1022-6.

Cavallari, Lilia and Federico Etro. 2017. Demand, markups and the business cycle. Bayesian estimation and quantitative analysis in closed and open economies, University of Venice, WP No. 09.

Chamley, Christophe. 1986. Optimal taxation of capital income in general equilibrium with infinite lives. Econometrica 54(3): 607-22.

Chatterjee, Satyajit, and Russell Cooper. 2014. Entry and exit, product variety, and the business cycle. Economic Inquiry 52(4):1466-84

Chevalier, Judith, Anil Kashyap, and Peter Rossi. 2003. Why don't prices rise during periods of peak demand? Evidence from scanner data. American Economic Review 93(1):15-37.

Colciago, Andrea, and Federico Etro. 2010. Real business cycles with Cournot competition and endogenous entry. Journal of Macroeconomics 32(4):1101-17.

Colciago, Andrea. 2016. Endogenous market structures and optimal taxation. Economic Journal 126(594):1441-83.

Dhingra, Swati and John Morrow. 2019. Monopolistic competition and optimum product diversity under firm heterogeneity, Journal of Political Economy, in press.

Dixit, Avinash, and Joseph Stiglitz. 1977. Monopolistic competition and optimum product diversity. American Economic Review 67:297-308.

Etro, Federico, and Andrea Colciago. 2010. Endogenous market structures and the business cycle. Economic Journal 120: 1201-34

Etro, Federico. 2016a. The Ramsey model with monopolistic competition and general preferences. Economics Letters 145:141-4.

Etro, Federico. 2016b. Endogenous market structures in the credit market and Ricardian equivalence. Economics Letters 140:14-8.

Fally, Thibault. Integrability and generalized separability. Unpublished paper. U.C. Berkeley: 2018.

Feenstra, Robert. 2003. A Homothetic utility function for monopolistic competition models without constant price elasticity. Economics Letters 78(1):79-86.

Feenstra, Robert. 2018. Restoring the product variety and pro-competitive gains from trade with heterogeneous firms and bounded productivity. Journal of International Economics 110(C:16-27.

Ghironi, Fabio. 2018. Macro needs micro. Oxford Review of Economic Policy 34(1-2):195-218.

Ghironi, Fabio, and Marc Melitz. 2005. International trade and macroeconomic dynamics with heterogenous firms. Quarterly Journal of Economics 120:865-915.

Gorman, William Moore. 1987. Separability. In The new Palgrave: A dictionary of economics, volume 4. London: Macmillan Press, 305-11.

Hanoch, Giora. 1974. Production and demand models with direct or indirect implicit additivity. Econometrica 43(3):395-419.

Kimball, Miles. 1995. The quantitative analytics of the basic neomonetarist model. Journal of Money, Credit and Banking 27: 1241-77.

Kydland, Finn, and Edward Prescott. 1982. Time to build and aggregate fluctuations. Econometrica 50(6):1345-70.

La Croce, Carla and Lorenza Rossi. 2014. Endogenous entry, banking, and business cycle, DEM Working Paper No. 072, University of Pavia.

Lewis, Vivien, and Roland Winkler. 2015. Product diversity, demand structures and optimal taxation. Economic Inquiry 53(2): 979-1003.

Lerner, Abba. 1934. The concept of monopoly and the measurement of monopoly power. Review of Economic Studies 1(3): 157-75.

Lucas, Robert, and Nancy Stockey. 1983. Optimal fiscal and monetary policy in an economy without capital. Journal of Monetary Economics 12(1):55-93. 
Matsuyama, Kiminori. Engel's law in the global economy: Demand-induced patterns of structural change and trade across countries. Northwestern University: Unpublished paper, 2017.

Matsuyama, Kiminori and Philip Ushchev, 2017, Beyond CES: Three alternative classes of flexible homothetic demand systems, CEPR DP12210.

Melitz, Marc, and Gianmarco Ottaviano. 2008. Market size, trade, and productivity. Review of Economic Studies 75:295-316.

Nekarda, Chris and Valery Ramey. 2013. The cyclical behavior of the price-Cost markup, NBER WP No. 19099.

Nocke, Volker, and Nicolas Schutz. 2018. Multiproduct-firm oligopoly: An aggregative games approach. Econometrica 86(2): 523-57.

Ottaviano, Gianmarco. 2012. Firm heterogeneity, endogenous entry, and the business cycle. NBER International Seminar on Macroeconomics 8(1):57-86.

Pollak, Robert. 1972. Generalized separability. Econometrica 40(3):431-53.

Poutineau, Jean-Christophe, and Gauthier Vermandel. 2015. Financial frictions and the extensive margin of activity. Research in Economics 69(4):525-54.

Ravn, Morten, Stephanie Schmitt-Grohé, and Martin Uribe. 2006. Deep habits. Review of Economic Studies 73(1):195-218.

Ravn, Morten, Stephanie Schmitt-Grohé, and Martin Uribe. 2008. Macroeconomics of subsistence points. Macroeconomic Dynamics 12(S1):136-47.

Romer, Paul. 1986. Increasing returns and long-run growth. Journal of Political Economy 94(5):1002-37.

Romer, Paul. 1990. Endogenous technological change. Journal of Political Economy 98(5):S71-102.

Rotemberg, Julio, and Michael Woodford. 1992. Oligopolistic pricing and the effects of aggregate demand on economic activity. Journal of Political Economy 100(6):1153-207.

Rotemberg, Julio, and Michael Woodford. 2000. The cyclical behavior of prices and costs: Chapter 16. In Handbook of macroeconomics, volume 1, edited by J. B. Taylor and M. Woodford. Elsevier, London, 1051-135.

Savagar, Anthony. 2017. Firm dynamics, dynamic reallocation, variable markups, and productivity behaviour (Unpublished paper). University of Kent.

Savagar, Anthony and Huw Dixon. 2017. Firm entry, excess capacity and aggregate productivity (Unpublished paper). University of Kent.

Stroebel, Johannes and Joseph Vavra. 2018. House prices, local demand and retail prices. Journal of Political Economy, in press. 